\title{
An E-Government-Integration Framework for County Governments in Kenya
}

\author{
Florence K. Maweu ${ }^{1}$, Josphat Karani ${ }^{2}$ \\ ${ }^{1}$ Department of computing and IT, Jomo Kenyatta University of Agriculture and Technology, Box 62000-00200-Nairobi-Kenya \\ ${ }^{2}$ Department of computing and IT, Kirinyaga University College, Box 143-Kutus, Kenya
}

\begin{abstract}
With the emergence of information and communication technologies (ICTs) ande-services, more and more governments'agencies are investing heavily in e-government design and implementations. The current trend of employing whole-of government approach helps break the bureaucratic model of delivering public services to allow for a more integrated approach. However, raising the effectiveness and quality of e-government services is not only a matter of leading edge technologies but also it involves visionary leadership, clear objectives and a sound infrastructural execution mechanism. The study examines the level of implementation of integrated e-government in the county government offices in Kenya.Mixed methodapproachwas employed with the use of structured questionnaires in selected government offices. Purposive sampling technique wasused where 36 officers with significant experience of e-government projects ware sampled for data collection. The study used the lessons learned from the literature review and the survey results to propose an integrated e-government framework and its accompanying prototype to validate the framework correctness. A specific usage is presented and further proves that the framework accomplishes its interoperability function.
\end{abstract}

Keywords: E-government, county government, integration, portal, interoperability

\section{Background}

The current technological trend that is taking place all over the world is forcing public and private sectors to re-engineer their strategies to more unified systems in public service delivery. A survey by [9] observes that, a new kind of rationalization has been introduced in the public sector by the use of modern information and communication technologies (ICTs). Increasingly the use of these technologies is gradually leading to transformational shifts in public policy, processes and functions. [3] refers to this convergence of government and technology that has the potential to transform public administration and the citizens ${ }^{\text {ee }}$ experience as e-government.

Before implementing e-government considerations should be put in place to address inter-agency issues and the different institutional and collaboration contexts in the particular area where the systems will be used. To facilitate inter-agency and inter-ministerial flow of information, a clear set of strategy is therefore deemed important.

This study therefore suggest a suitable dynamic framework and an e-government architecture that aids in shaping up egovernment in the county governments and facilitate a clear flow of information from the county e-government system to the ministries in the national e-government.

\section{An Overview of e-Government Integration and ICT in Public Sector}

With the development of e-government, an increasing number of governments around the world are trying to define a high-level architectural framework for re-engineering their information systems and business processes. The need to define an ,Enterprise Architecture ${ }^{\text {ee }}$ (EA) showing how their e-government vision is expressed through the structure and dynamics of their organization, and how all parts of the organization work together to achieve it becomes profound government agenda. Successful and mature e-government can only be achieved through a process of building organizational infrastructures that enable innovative action strategies to thrive in the culture of interoperability

\section{Knowledge Gap}

Many scholars in the world have studied different aspects of e-government and ESD strategies.[2] in their research argued on the need for common e-GI to avoid duplication by the different agencies involved in public service which increases cost and complexity of government operations.

[4] Studied Information Systems Implementation in State Corporations but with abiason State Parastatals. They proposed a framework to guide in coming up with user-based e-government systems. In their study on Promoting transparency and accountability through ICTs, social media, and collaborative e-government [5] identified multiple perspectives on government transparency efforts, the role of ICTs and social media in these efforts, and the ability of e-government initiatives to foster collaborative transparency through embedded ICTs and social media.

[4] their study on Bridging the gaps between e-government practice and research emphasized that there are persisting differences and discourses between public administration and e-government reports and journals. They identified some conceptual gaps related to emerging issues like egovernment evaluation, engagement with end-users and connection gaps between policy, practice and research.

Accordingly, [5] argued that any successful e-government service should satisfy the following user benefits: easy to use; accessibility and inclusivity; confidentiality and privacy.[8] proposed framework that offers database replication and 


\section{International Journal of Science and Research (IJSR) \\ ISSN (Online): 2319-7064}

Index Copernicus Value (2013): 6.14 | Impact Factor (2014): 5.611

connectivity functionalities for the Central Database. [5] argued that any attempt to create user-centered e-government services must account for a number of essential elements including the ability to use e-government, to build trust and to tziee-government to establish social and institution requirements among others. [1] in their article on positioning e-Government services in the credence-based setting in India identified thenewe-governmentenvironment under "credence based" service setting that emphasizes user"s perspective. [7]in their editorial paper came up with a conceptual model of e-government collaboration forces. The paper clarifies on the motivation behind collaboration in governments which varies across nations.

From the above literature, it is clear that there is lack of a holistic Study related to e-government frameworks, e-vision and portal implementation and development forcounty systems in Kenya. This is the gap the study is trying to fill.

\section{Research Methodology}

The research study adopted mixed methodsin the research design to come up with the expected results. To identify the level of e-government implementation initiatives and their influence on public service delivery in Kenya a survey design was adopted where the views of relevant public office holders in the county government on electronic service delivery and public services dissemination was carried to ensure an informed discussion, evaluation and conclusion. The architecture was adopted from successful global trends, while the prototype was designed using the Agile methodology which allows for prototyping.

\section{Conceptual Model: Architecture Overview}

The conceptual model of the architecture shows the National government systems and the county portal joined up by the e-government integration framework

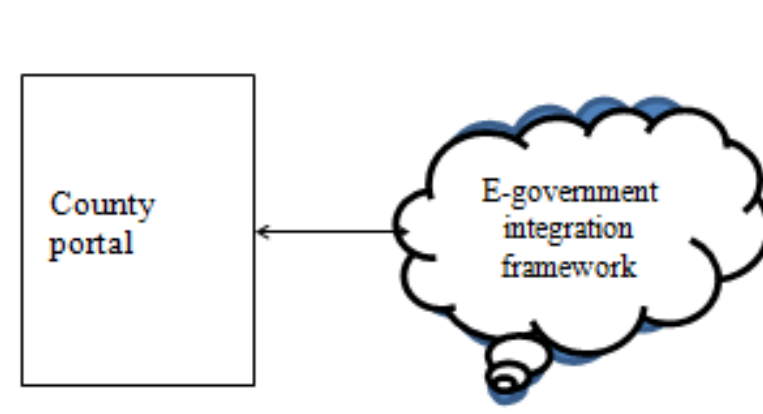

County systems in one stop shop
Inter-Operability framework

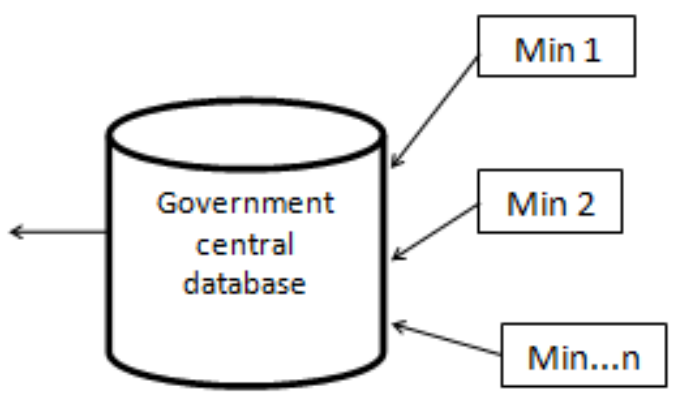

National government systems

Figure 1: Architecture overview

\section{Proposed E-government Architecture}

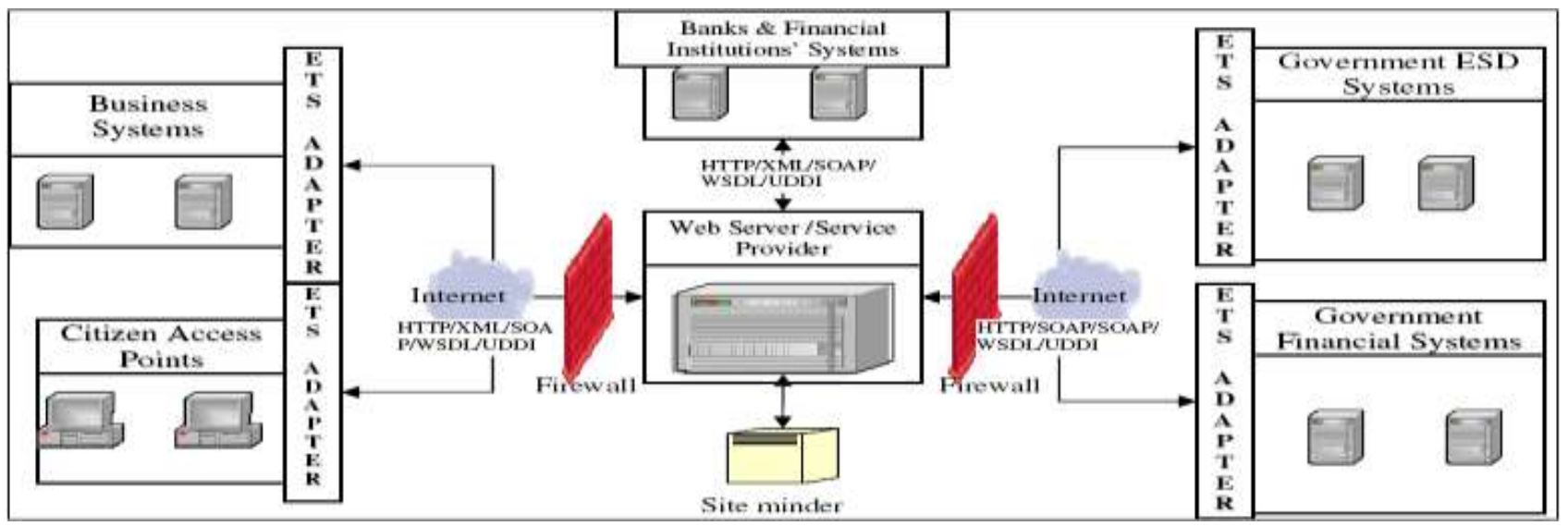

Figure 2: The E-government architecture framework

Users will be limited to using and accessing information and services only made for them through the use of security firewalls. The government will interact with citizens, businesses financial institutions and other stakeholders through its in house systems, systems hosted on the web server, and systems maintained by businesses and financial institutions with the facilitation of internet service providers. Various transactions and services will be accessed through a central portal. Site Minder which is a centralized Web access management system will enable user authentication, policybased authorization, identity federation, and auditing of access to web applications and portals. Various technologies and components such as SOAP, HTTPS, HTTP and XML will be adopted as integration enablers for the diverse systems.The resulting architecture of service delivery, predicated on more seamless governance, is reflected in its 


\section{International Journal of Science and Research (IJSR)}

ISSN (Online): 2319-7064

Index Copernicus Value (2013): 6.14 | Impact Factor (2014): 5.611

earliest iteration in what the jurisdictions at times refer to as "joined up" government[9].

\section{Strategies Common to Successful e- Government-Integration for Counties in Kenya}

I. Creating a collaborative network-based governance framework. Collaborative mechanisms for service integration depend on the creation of common information architectures. A more robust set of conditions and learning opportunities for accelerating the development of e-based governance mechanisms that transcend traditional jurisdictional silos need to be exploited.

II. Creating a common technology infrastructure. Collaboratively the Kenyan government could adopt service architecture like the one proposed that emphasizes interoperable information systems service across all agencies.

III. Agreeing on a common identity management framework. This framework would serve as a foundation for the development of a national system to create a common approach to identify individuals participating in government activities.

\section{The Proposed County Portal Snapshot}

Since most government services are held at the county portal the citizens will be accessing them in one-stop shop as shown:

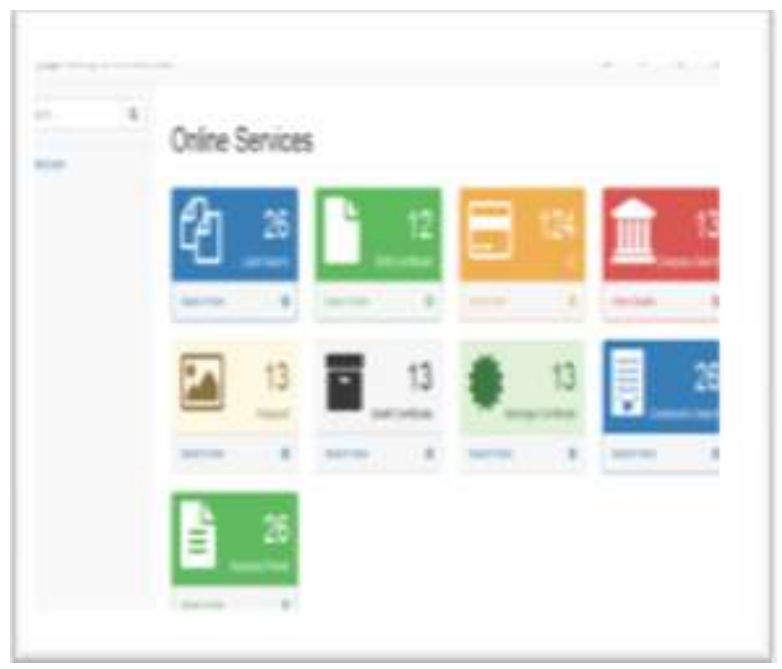

Figure 3: The proposed county Portal

\section{Implementing the Portal using a Specific Usage: New business registration at the County Portal}

The following is the snapshot for anew business registration by a citizen at the county level where the main database will be held by the ministry of industrialization at the National government a Nen Busuess regatiaten

Otak Kingegaten Cottcie Sart.

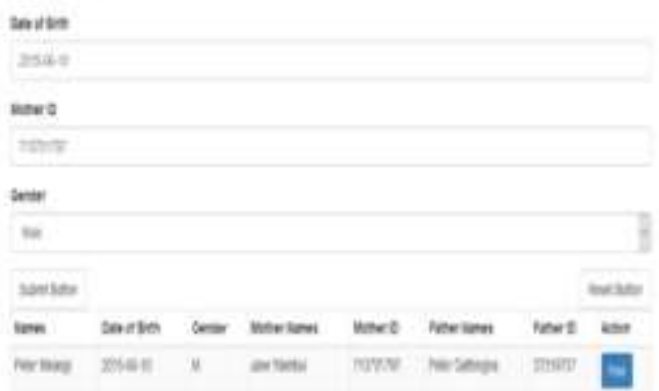

Figure 4: New business registration at the proposed county portal

\section{References}

[1] Amritesh, et al.,(2013). Positioning e-government services in the credence based setting, Transforming Government: People, ProcessandPolicyVol.7No.3,2013

[2] Anu Paul et al., (2014). A Framework for e-Government Interoperability in Indian Perspective International Journal of Computer Information Systems and Industrial Management Applications. ISSN 2150-7988Volume 6(2014) pp.582-591

[3] Boateng, V. (2009) Electronic/Mobile Government in Africa: Building Capacity in Knowledge Management through Partnership. Application Systems Ghana Information and Communications Technology Directorate, Ghana Country Presentation. Addis Ababa, Ethiopia.

[4] EndritKromidha et al., (2013) bridging the gaps between e-government practice and research: A meta-study for policy development: International Journal of Public Sector Management Vol.27No.1, 2014 pp. 66-84.

[5]JohnCarloBertot, (2011). Promoting transparency and accountability through ICTs, social media, and collaborative e-government: Transforming Government: People, Process and Policy Vol.6No.1, 2012 pp. 78-91q Emerald GroupPublishingLimited1750-6166

[6] Magutu, and Lelei, J. K.(2010).Information systems implementation in state corporations; a critical evaluation of the process and challenges in Kenyan parastatals, African Journal of Business and Management(AJBUMA).vol.1(2010),pp.237-259

[7] Soon AeChun et al.,(2012) Collaborative egovernment Transforming Government: People, Process and Policy Vol.6No.1,2012 pp.5-12 q Emerald Group Publishing Limited 1750-6166

[8] Suhail Madoukh (2014) a SOA-Based e-Government Data Integration: International Arab Journal of $e$ Technology, Vol.3, No.3, January 2014

[9] UN - United Nations (2012) United Nations eGovernment Survey 2012, e-Government for the people. Department of Economic and Social Affairs Division for Public administration and Development Management 